Plant Tissue Cult. \& Biotech. 23(2): 221-229, 2013 (December)

$\underline{\text { PTC\&B }}$

\title{
Micropropagation of Salacia reticulata - an Endangered Medicinal Plant
}

\section{G. Dhanasri, M. Srikanth Reddy, B. Naresh and Prathibha Devi Cherku*}

Plant Biotechnology and Molecular Genetics Laboratory, Department of Botany, Osmania University, Hyderabad 500007, India

Key words: Micropropagation, Salacia reticulata, Multiple shoots, In vitro rooting

\begin{abstract}
An efficient protocol of axillary bud proliferation and direct organogenesis has been developed for Salacia reticulata, a highly important medicinal plant. Overexploitation for its antidiabetic and antioxidant properties concentrated in roots and stem has caused it to be endangered, thereby the need for its conservation. Propagation of $S$. reticulata in vitro is a promising way for its conservation. To develop the micropropagation protocol, the germplasm was screened for selection of a suitable ecotype with high content of mangiferin estimated with High Performance Liquid Chromatography technique. Nodal segments were cultured on MS supplemented with different growth regulators. The most efficient shoot multiplication was obtained with the supplementation of BA and IAA $(3.5+0.5 \mathrm{mg} / \mathrm{l})$. Elongation of the micro-shoots was achieved by subculture every 20 days. The elongated micro-shoots were efficiently rooted in vitro on half strength MS supplemented with IBA. Plantlets were successfully established in the soil in 6 - 8 weeks and were morphologically similar to those of the source plant. The protocols developed presently for direct shoot regeneration and rootinduction could be successfully applied for development of high quality planting stocks.
\end{abstract}

\section{Introduction}

Salacia reticulata a medicinally important, endangered plant that belongs to the family Celastraceae is a woody, climbing shrub, commonly known as Saptarangini or Kotala Himbutu in India. The distribution of S. reticulata is restricted to the eastern India and Sri Lanka. The flowering period is from February to April and the fruiting starts from April to May. Fruits are large, tuberculate and bright pinkish orange in colour. Seed is immersed in pulp. Seed germination takes a long time and percentage of germination is also low.

"Author for correspondence: <prathi56@yahoo.com>. 
Since ancient times, Salacia reticulata was used as medicine by Indian tribes and later Ayurvedic (alternative medicine) practitioners started to use it to treat diabetes for normalizing blood sugar and insulin levels (Tissera and Thabrew 2001, Yoshikawa et al. 2002a, b, Jayawardane et al. 2005). Compounds such as mangiferin and sulfonium ion derivatives-kotalanol and salacinol have been identified in root and stems of S. reticulata, which are potent alpha-glucosidase inhibitors (Yoshikawa et al. 1998, Kumara et al. 2005). Mangiferin also inhibits aldose reductase activity, thereby delaying the onset or progression of diabetic complications (Mukherjee et al. 2006). Due to its medicinal importance, it is becoming endangered and there is a need for its conservation and large scale production. There are no earlier reports on seed based, in vivo propagation or in vitro propagation of $S$. reticulata. In this study we report a reproducible and reliable micropropagation protocol developed for its efficient propagation.

\section{Materials and Methods}

A survey was carried out in different forests of Andhra Pradesh State of India for location of S. reticulata plants and they were identified at three different forests of the districts, namely Chittoor, Kurnool and Vizianagaram with the help of satellite pictures of the Andhra Pradesh State Remote Sensing Applications Centre (APSRAC). Permission of the Department of Forestry, Government of Andhra Pradesh was obtained to collect the plants, roots and their seeds. The plants were collected from eight locations, transferred and established in the Medicinal and Botanical Garden of the Department of Botany, Osmania University Hyderabad, India. Morphological characteristics of the accessions of S. reticulata were studied and their biochemical analyses were made in order to determine the range of of variation in the content of mangiferin through High Performance Liquid Chromatography (HPLC). Thereafter, the accession containing the highest content of mangiferin was chosen to develop an efficient micropropagation protocol.

A total of eight accessions of S. reticulata were collected for the study from Chittoor (G1, G2 and G3), Khammam (G4, G5 and G6) and Vizianagaram districts (G7 and G8) of the Andhra Pradesh State of India.

Using the following criteria, namely the plant height, shape, size and color of the leaf, inflorescence, the color of the flower and the fruit and 100-seed-weight of the eight accessions of $S$. reticulata were determined.

To estimate the variation in the mangiferin content, the roots and stems of $S$. reticulata collected from the three districts viz. Chittoor, Khammam and Vizianagaram were shade dried, chopped, finely powdered and extracted with methanol. The methanolic extracts of the root and stem of S. reticulata were 
prepared and subjected to High Performance Liquid Chromatography (HPLC) for quantitative and qualitative studies. The HPLC was carried out with Octadecyl Silance (ODS) column C1 eight Phenomenex, Type: Luna $5 \mu$ C 18 (2) with the following parameters.

Mobile phase : Solvent A (Buffer): Dissolve $0.136 \mathrm{gms}$ of potassium dihydrogen orthophosphate $\left(\mathrm{KH}_{2} \mathrm{Po}_{4}\right)$ in $500 \mathrm{ml}$ HPLC grade water, add $0.5 \mathrm{ml}$ of orthophosphoric acid $\left(\mathrm{H}_{3} \mathrm{PO}_{4}\right)$ and make up to $1000 \mathrm{ml}$.

Solvent B: $100 \%$ acetonitrile

Column : ODS (Octadecyl silence) C1 eight Phenomenex: Type: Luna $5 \mu \mathrm{C}$ 1eight(2), size: $250 \times 4.60 \mathrm{~mm} 5 \mu$ micron

Flow rate $\quad: \quad 1.5$

Wave length : $\quad 254 \mathrm{~nm}$

Standard preparation : $0.125 \mathrm{mg} / \mathrm{ml}$ of mangiferin (in $10 \% \mathrm{DMF}, 90 \%$ methanol)

Sample preparation : $\quad \sim 10 \mathrm{mg} / \mathrm{ml}$ of (in 10\% DMF, 90\% methanol)

Isocratic condition : $\quad 25 \%$ acetonitrile in buffer

Nodal explants of the G2 accession of $S$. reticulata (2 to $3 \mathrm{~cm}$ in length) were used after removing the leaves from the node retaining the petiole. The explants were surface sterilized by very stringent methods that included washing in running tap water, treatment with Teepol, sodiumhypochlorite, $70 \%$ alcohol and $0.1 \%$ mercuric chloride. The explants were inoculated into sterile $25 \times 150 \mathrm{~mm}$ culture tubes containing autoclaved culture medium.

The MS containing 3\% (w/v) sucrose, and $0.8 \%(\mathrm{w} / \mathrm{v})$ agar-agar (Hi-media) was used with different combinations of growth regulators with $\mathrm{pH}$ of 5.8 and autoclaved for $15 \mathrm{~min}$ at $121^{\circ} \mathrm{C}$ at $15 \mathrm{lbs}$ pressure. Thirty explants were inoculated for each experiment with three replications with a total of 90 . The cultures were maintained in a sterile growth room with a $16 \mathrm{hrs}$ photoperiod at $25 \pm 2^{\circ} \mathrm{C}$ at a light intensity of $60 \mu \mathrm{Em}^{2} / \mathrm{s}$ and $65 \%$ relative humidity.

The growth regulators consisted of viz. BAP and $\mathrm{Kn}$ and viz. IBA, IAA used in different combinations with MS for shoot initiation: BAP (2.0 to $4.0 \mathrm{mg} / \mathrm{l})+\mathrm{IBA}$ (0.5 to $1.5 \mathrm{mg} / \mathrm{l}), \mathrm{BAP}$ (2.0 to $4.0 \mathrm{mg} / \mathrm{l})+\mathrm{IAA}(0.5$ to $1.5 \mathrm{mg} / \mathrm{l}), \mathrm{Kn}(2.0$ to $4.0 \mathrm{mg} / \mathrm{l})$ + IBA (0.5 to $1.5 \mathrm{mg} / \mathrm{l}), \mathrm{Kn}$ (2.0 to $4.0 \mathrm{mg} / \mathrm{l})$ + IAA (0.5 to $1.5 \mathrm{mg} / \mathrm{l})$.

In vitro induced shoots were subcultured in the same media at an interval of 20 days for elongation. For root induction, well developed shoots were inoculated on different root initiation media comprising half strength MS with different concentrations of IBA or NAA. The micro-shoots with roots were transferred to MS for further growth and finally washed before transfer to small 
pots containing soil + vermicompost $(2: 1)$ for hardening and acclimation. The pots were covered with polythene bags to maintain high relative humidity for two weeks and transferred to the glasshouse after emergence of new leaves and later to the field.

\section{Results and Discussion}

All the accessions of $S$. reticulata were more or less morphologically similar except for a few characters. The details are presented below.

The plants are perennial woody climbing shrubs and the height of the twoyear-old plants ranged from $170-191 \mathrm{~cm}$. The highest value was recorded in the G3 accession $(191 \mathrm{~cm})$.

The leaves were opposite, glabrous and shining, ovate or obovate-oblong, coriaceous with the length of the older leaf blade reaching up to $11-13 \mathrm{~cm}$ in case of the G1, G2 and G3 accessions.

The plants attained maturity in two years and flowered (about 30 - 50 per branch) during January-February. The inflorescence was axillary in fascicles and flowers were small, fascicled on woody branches on axillary tubercles or cymes. The color of the flower was yellowish green, petals ovate, acute and sepals glabrous, with three stamens continuous with the disk. The highest number of flowers viz. 50 per branch were found in the G7 and G8 accessions.

The fruits were big, tuberculate, orange to bright pinkish orange with 1 - 3 seeds immersed in the pulp, seeds after drying are brown in color and 100 seed weight varied from 31.8 to $33.9 \mathrm{~g}$ with the highest 100-seed-weight recorded in the G5 accession (33.9 g).

The height of the plants collected from Chittoor district (G1, G2 and G3) was the highest, and the length of their leaf blade was also the highest. The maximum number of flowers (50/branch) were observed in G7 and G8-accessions. Although the G1, G2 and G3 accessions were the tallest, the yield of flowers and 100-seedweight was higher in the latter. The highest 100-seed-weight was recorded in the G5 accession (33.9 g).

The aqueous and methanolic extracts of the root and stem was reported to produce many pharmacologically active compounds (Ghavami et al. 2001). The roots and stems of G1, G2 and G3 accessions of Chittoor forest had 0.89 and $0.06 \%$ of mangiferin content respectively (Table 1 ). Whereas, mangiferin content, of roots and stems of G4, G5 and G6 accessions of Khammam forest was 0.29 and $0.01 \%$, respectively, those of G7 and G8 accessions of Vizianagaram forest was 0.21 and $0.02 \%$, respectively. Hence, the accessions of Chittoor forest had the 
highest content of mangiferin and the G2 accession was therefore selected for the micropropagation studies.

Table 1. Content of mangiferin present in the roots and stems of Salacia reticulata collected from four different locations of A.P.

\begin{tabular}{lc}
\hline Sample & Mangiferin (\%) \\
\hline Roots collected from Chitoor forest & 0.89 \\
Stems collected from Chitoor forest & 0.06 \\
Roots collected from Khammam forest & 0.29 \\
Stems collected from Khammam forest & 0.01 \\
Roots collected from Vizianagaram forest & 0.21 \\
Stems collected from Vizianagaram forest & 0.02 \\
\hline
\end{tabular}

Micropropagation is an efficient tool for the conservation and mass multiplication of endangered important medicinal plants like $S$. reticulata. Presently, the initiation of shoots from axillary buds of the G2 accession of $S$. reticulata was observed after the first subculture (Fig. 1, Table 1). Although the use of BA or Kn alone with MS could induce axillary buds in preliminary studies, profuse multiple shoots could be induced only with addition of an auxin. Higher efficiency in shoot regeneration in terms of the number of shoots produced was obtained with the combinations of BA $(3.5 \mathrm{mg} / \mathrm{l})$ and either auxin (9.80 \pm 1.10 and $10.64 \pm 0.96$ with $1.0 \mathrm{mg} / \mathrm{l} \mathrm{IBA}$ and $0.5 \mathrm{mg} / \mathrm{l} \mathrm{IAA}$, respectively) followed by the combination of $\mathrm{Kn}(4.0 \mathrm{mg} / \mathrm{l})$ and either auxin $(9.35 \pm 1.86$ and $9.65 \pm 1.76$ with $1.0 \mathrm{mg} / \mathrm{l} \mathrm{IBA}$ and $0.5 \mathrm{mg} / \mathrm{l} \mathrm{IAA}$, respectively). However, the supplementation of IAA resulted in a higher response than that of IBA. Further, $0.5 \mathrm{mg} / \mathrm{l}$ IAA could produce shoots with higher efficiency than $1.0 \mathrm{mg} / \mathrm{l}$ of IBA. The results indicate that BA has higher potential to promote micropropagation in S. reticulata than $\mathrm{Kn}$ and supplementation of IAA was more advantageous than IBA. It was also observed that the highest concentration of BA $(4 \mathrm{mg} / \mathrm{l})$ with IAA resulted in formation of callus at the base of the explant after subculture and was therefore not found suitable. Therefore, the supplementation of IAA resulted in a higher response than that of IBA. This shows the positive synergistic interaction of BA and Kn with the auxins at low concentration resulting in highest efficiency. Similar results were reported with Gymnema sylvestre (Reddy et al. 1998). An increase in the auxin concentration with the higher concentration of cytokinins resulted in the production of callus at cut ends of nodal segments possibly due to the accumulation of auxins which stimulates the cell proliferation in the presence of cytokinins (Marks and Simpson 1994). Similar findings were reported in medicinal plants like Tylophora indica (Sharma and Chandel 1992), Holostemma annulare (Sudha et al. 1998), Holostemma ada-kodien (Karmarkar et al. 2001). 
Table 2. Effect of growth regulators (combination of a BA or Kn and IBA or IAA) on multiple shoot induction from nodal explants of $S$. reticulata.

\begin{tabular}{|c|c|c|c|}
\hline $\begin{array}{l}\text { Growth regulators } \\
(\mathrm{mg} / \mathrm{l})\end{array}$ & $\begin{array}{c}\text { Number of shoots } \\
\text { Mean } \pm \text { SE }\end{array}$ & $\begin{array}{c}\text { Growth regulators } \\
(\mathrm{mg} / \mathrm{l})\end{array}$ & $\begin{array}{c}\text { Number of shoots } \\
\text { Mean } \pm \text { SE }\end{array}$ \\
\hline Control & $1.00 \pm 0.00$ & Control & $1.00 \pm 0.00$ \\
\hline BA+IBA & & BA+IAA & \\
\hline $2.0+0.5$ & $1.52 \pm 0.33$ & $2.0+0.5$ & $1.60 \pm 0.80$ \\
\hline$\prime \prime+1.0$ & $1.95 \pm 0.51$ & $2.0+1.0$ & $1.90 \pm 0.88$ \\
\hline " +1.5 & $1.60 \pm 0.27$ & $2.0+1.5$ & $2.22 \pm 1.33$ \\
\hline $2.5+0.5$ & $2.79 \pm 0.39$ & $2.5+0.5$ & $2.00 \pm 0.58$ \\
\hline$"+1.0$ & $2.30 \pm 0.62$ & $2.0+1.0$ & $2.54 \pm 1.22$ \\
\hline , +1.5 & $3.40 \pm 0.35$ & $2.0+1.5$ & $4.02 \pm 1.20$ \\
\hline $3.0+0.5$ & $6.05 \pm 1.20$ & $3.0+0.5$ & 4. $89 \pm 1.45$ \\
\hline$\prime \prime+1.0$ & $8.22 \pm 0.70$ & $3.0+1.0$ & $6.65 \pm 1.40$ \\
\hline$\prime \prime \quad+1.5$ & $7.85 \pm 0.62$ & $3.0+1.5$ & $7.95 \pm 0.72$ \\
\hline $3.5+0.5$ & $9.20 \pm 0.96$ & $3.5+0.5$ & $10.64 \pm 0.96$ \\
\hline$\prime \prime+1.0$ & 9. $80 \pm 1.10$ & $3.5+1.0$ & $10.34 \pm 1.50$ \\
\hline$\prime \prime+1.5$ & $9.40 \pm 0.98$ & $3.5+1.5$ & $9.00 \pm 0.65$ \\
\hline $4.0+0.5$ & $8.00 \pm 1.38$ & $4.0+0.5$ & $8.78 \pm 1.64$ \\
\hline$\prime \prime+1.0$ & $7.20 \pm 1.50$ & $4.0+1.0$ & $7.50 \pm 2.05$ \\
\hline$\prime \prime \quad+1.5$ & $7.00 \pm 1.80$ & $4.0+1.5$ & $6.35 \pm 2.00$ \\
\hline $\mathrm{Kn}+\mathrm{IBA}$ & & Kn+IAA & \\
\hline $2.0+0.5$ & $1.42 \pm 0.43$ & $2.0+0.5$ & $1.50 \pm 1.35$ \\
\hline$\prime \prime+1.0$ & $1.70 \pm 0.60$ & $2.0+1.0$ & $2.05 \pm 0.87$ \\
\hline$\prime \prime \quad+1.5$ & $1.80 \pm 0.80$ & $2.0+1.5$ & $2.40 \pm 1.35$ \\
\hline $2.5+0.5$ & $2.25 \pm 0.90$ & $2.5+0.5$ & $2.65 \pm 0.62$ \\
\hline , +1.0 & $2.32 \pm 0.85$ & $2.5+1.0$ & $4.50 \pm 1.66$ \\
\hline ", +1.5 & $4.10 \pm 1.30$ & $2.5+1.5$ & $4.02 \pm 1.75$ \\
\hline $3.0+0.5$ & $4.05 \pm 0.76$ & $3.0+0.5$ & $4.00 \pm 0.70$ \\
\hline$\prime \prime+1.0$ & $6.84 \pm 1.5$ & $3.0+1.0$ & $5.10 \pm 1.10$ \\
\hline$\prime \prime \quad+1.5$ & $8.35 \pm 1.62$ & $3.0+1.5$ & $5.85 \pm 0.40$ \\
\hline $3.5+0.5$ & $7.68 \pm 0.70$ & $3.5+0.5$ & $8.90 \pm 0.56$ \\
\hline$\prime \quad+1.0$ & $8.82 \pm 1.50$ & $3.5+1.0$ & $8.98 \pm 2.36$ \\
\hline$\prime \prime \quad+1.5$ & $9.02 \pm 1.64$ & $3.5+1.5$ & $9.02 \pm 2.33$ \\
\hline $4.0+0.5$ & $9.05 \pm 2.10$ & $4.0+0.5$ & $9.65 \pm 1.76$ \\
\hline$\prime \prime \quad+1.0$ & $9.35 \pm 1.86$ & $4.0+1.0$ & $9.00 \pm 1.35$ \\
\hline$\ldots+1.5$ & $8.76 \pm 1.78$ & $4.0+1.5$ & $8.20 \pm 0.85$ \\
\hline
\end{tabular}

The elongated micro-shoots (of 3 - $4 \mathrm{~cm}$ in length with 2 - 3 internodes) were transferred to root initiation media and roots was observed after 25 - 40 days. Therefore, in vitro rooting was successfully achieved with the supplementation of 
IBA (2.0 mg/l) (Table 3, Fig. 1), similar to reports in Adhatoda vasica (Azad et al. 1999) and Cunila galioides (Fracaro and Echeverrigary 2001).

Table 3. Effect of supplementation of IBA or NAA to half strength MS for in vitro rooting of Salacia reticulata.

\begin{tabular}{lcc}
\hline $\begin{array}{c}\text { Half strength MS + IBA } \\
(\mathrm{mg} / \mathrm{l})\end{array}$ & $\begin{array}{c}\text { Half strength MS }+ \\
\text { NAA }(\mathrm{mg} / \mathrm{l})\end{array}$ & $\begin{array}{c}\text { No. of roots developed } \\
\text { Mean } \pm \text { SE }\end{array}$ \\
\hline 0.5 & -- & $0.30 \pm 0.55$ \\
1.0 & -- & $0.68 \pm 0.90$ \\
1.5 & -- & $2.70 \pm 1.48$ \\
2.0 & -- & $3.05 \pm 1.55$ \\
2.5 & - & $1.80 \pm 1.25$ \\
-- & 0.5 & $0.50 \pm 0.86$ \\
-- & 1.0 & $0.96 \pm 1.21$ \\
-- & 1.5 & $1.80 \pm 0.74$ \\
-- & 2.0 & $1.50 \pm 1.54$ \\
-- & 2.5 & $1.25 \pm 1.65$ \\
\hline
\end{tabular}

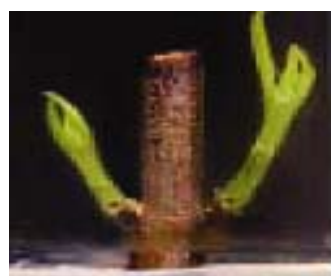

a
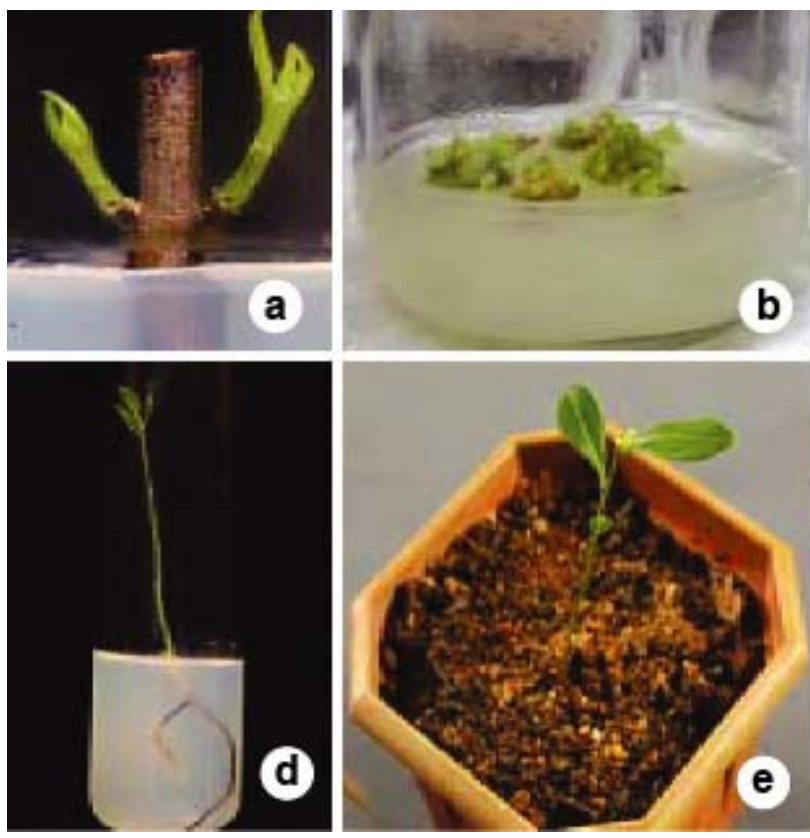
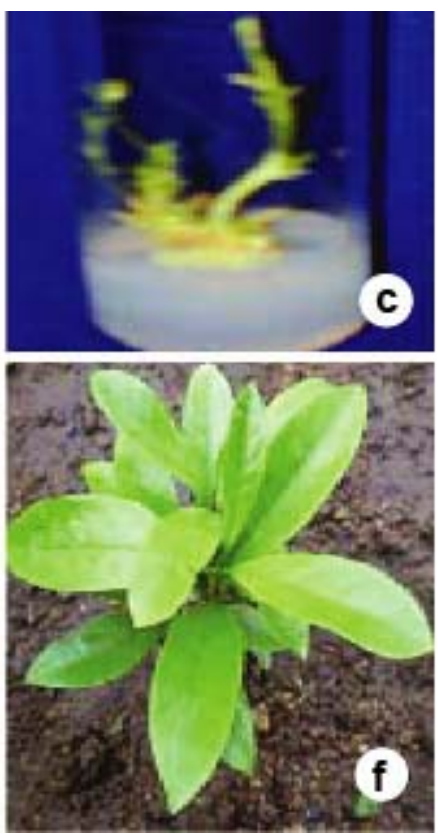

Fig. 1. Stages of micropropagation of Salacia reticulata : (a) Proliferation of shoot buds from nodal segment; (b) Initiation of multiple shoots after second subculture; (c) Elongated shoot; (d) In vitro rooted shoot; (e) Rooted plantlets transferred into small plastic pots for hardening; (f) Acclimatized plants after 3 - 4 months.

Micro-shoots with proper root system were subjected to two-week hardening and acclimation and shifted to the glasshouse and later to a shady place in the 
garden. Plantlets were successfully established in the soil in six - eight weeks and were morphologically similar to those of the source plant.

\section{Acknowledgments}

The financial help from the Department of Science and Technology, the Government of India through the award of a woman Scientist fellowship to G. Dhanasri is gratefully acknowledged.

\section{Reference}

Azad MAK, Amin MN and Begum F (1999) In vitro rapid regeneration of plantlets from cotyledon explants of Adhatoda vasica Nees. Plant Tissue Culture 9: 121-126.

Fracaro F and Echeverrigaray S (2001) Micropropagation of Cunila galioides, a popular medicinal plant of South Brazil. Plant Cell Tiss. Org. Cult. 64: 1-4.

Ghavami A, Johnston BD, Jensen MT, Svensson B and Pinto BM (2001) Synthesis of nitrogen analogues of salacinol and their evaluation as glycosidase inhibitors. J. Am. Chem. Soc. 123: 6268-6271.

Jayawardena MH, de Alwis NM, Hettigoda V and Fernando DJ (2005) A double blind randomised placebo controlled cross over study of a herbal preparation containing Salacia reticulata in the treatment of type 2 diabetes. J. Ethnopharmacol. 97(2): 215-18.

Karmarkar SH, Keshavachandran R, Nazeem PA and Girija D (2001) Hairy root induction in Adapathiyan (Holostemma ada-kodien K. schum.). J. Tropical Agric. 39: 102-107.

Marks TR and Simpson SE (1994) Factors affecting shoot development in apically dominant Acer cultivars in vitro. J. Hort. Sci. 69: 543-551.

Mukherjee PK, Maiti K, Mukherjee K and Houghton PJ (2006) Leads from Indian medicinal plants with hypoglycemic potentials. J. Ethnopharmacology 106: 1-28.

Reddy PS, Gopal GR and Sita GL (1998) In vitro multiplication of Gymnema sylvestre R. Br.-An important medicinal plant. Curr. Sci. 75: 843-845.

Ruvin Kumara, NKVM, Pathirana RN and Pathirana C (2005) Hypoglycemic activity of the root and stem of Salacia reticulata var. $\beta$-diandra in alloxan diabetic rats. Pharmaceutical Biol. 43: 219-225.

Sharma N and Chandel KPS (1992) Effect of ascorbic acid on axillary shoot induction in Tylophora indica (Burm. f.) Merrill. Plant Cell Tiss. Org. Cult. 29: 109-113.

Sudha CG, Krishnan PN and Pushpangadan P (1998) In vitro propagation of Holostemma annulare (Roxb.) K. Schum. A rare medicinal plant. In vitro Cell Dev. Biol. Plant. 34: 57-63.

Tissera MHA and Thabrew, MI (2001) Medicinal plants and ayurvedic preparations used in Sri Lanka for the control of Diabetes mellitus. A publication of the Department of Ayurveda, Ministry of Health and Indigenous Medicine, Sri Lanka. 
Yoshikawa M, Murakami T, Yashiro K and Matsuda H (1998) Kotalanol, a potent $\alpha$ glucosidase inhibitor with thiosugar sulfonium sulfate structure, from hypoglycemic ayurvedic medicine Salacia reticulata. Chem. Pharm. Bull. 46: 1339-1340.

Yoshikawa M, Morikawa T, Matsuda H, Tanabe G and Muraoka O (2002a) Absolute stereostructure of potent alpha-glucosidase inhibitor, salacinol, with unique thiosugar sulfonium sulfate inner salt structure from salacia reticulata. Bioorg. Med. Chem. 10: 1547-1554.

Yoshikawa M, Shimoda H, Nishida N, Takada M and Matsuda H (2002b) Salacia reticulata and its polyphenolic constituents with lipase inhibitory and lipolytic activities have mild antiobesity effects in rats. J. Nutr. 132: 1819-1824. 